\title{
ENERGIA, MEIO AMBIENTE E INOVAÇÃO TECNOLÓGICA
}

\section{F.J.P Costa ${ }^{1}$; M. G. Rodrigues ${ }^{2^{*}}$}

1 Universidade de Santiago de Compostela. 15782, Santiago de Compostela, Espanha.

2 Universidade Estácio de Sá. 20261-063, Rio de Janeiro-RJ, Brasil

*manoel.grodrigues@gmail.com

\section{RESUMO}

A problemática do desenvolvimento não pode ser mais abordada sem ter em linha de conta as questões energética e meio ambiental, assim como a íntima relação e a intensa interação existente entre ambas. De fato, a questão energética não pode ser analisada separadamente da problemática meio ambiental, e nem dos avanços no campo da inovação tecnológica, integrando-se de forma dinâmico-sistêmica e assim se posicionando face à questão do modelo de desenvolvimento a se configurar no bojo do processo de transição vivido pelo mundo desde os anos setenta do século XX. Este processo de transição, por sua vez, implica na passagem do Paradigma dos Combustíveis Fósseis ao Paradigma das Energias Renováveis também denominado de o Paradigma das Fontes Renováveis de Energia, não se prendendo apenas à problemática energética, mas simultaneamente às componentes ambiental e tecnológica. O novo modelo/estilo de desenvolvimento dever-se-á basear na sustentabilidade e na modernização tecnológica. Assim, o objetivo deste artigo é uma reflexão sobre a atual configuração energético-ambiental e o novo modelo de desenvolvimento que dela emerge, o qual se torna viável através do desenvolvimento tecnológico e da inovação.

PALAVRAS-CHAVE: Economia Global, Paradigmas, Energia, Tecnologia, Desenvolvimento.

\section{TITULO EM UM SEGUNDO IDIOMA (INGLÊS OU ESPANHOL)}

\begin{abstract}
The development problems can not be addressed without taking account of the environmental and energy issues, as well as the intimate relationship and the intense interaction between the two. In fact, the energy issue can not be analyzed separately from environmental issues, nor the advances in technological innovation, integrating dynamic-systemic way and so positioning address the issue of the development model to set the bulge the transition process experienced by the world since the seventies of the twentieth century. This transition, in
\end{abstract}

turn, implies the passage of Paradigm of Fossil Fuels to Renewable Energy also called the Paradigm of renewable sources of energy, not just holding the energy problem, but towards to environmental and technological components. It is within this relatively slow and long process, instigator of high levels of volatility, turbulence inducing and motor of technological innovation, which is (re) raises the question of the development model that defines how a new model/style development.

KEYWORDS: Global Economy, Paradigms, Energy, Technology, Development 


\section{INTRODUÇÃO}

A Primeira Revolução Industrial (PRI), ocorrida na Inglaterra entre os séculos XVIII e XIX, configurou o Paradigma dos Combustíveis Fósseis. Este primeiramente tomaria o carvão como base energético-produtiva. Já em finais do século XIX e início do século XX, no contexto da Segunda Revolução Industrial (SRI), entra em cena o petróleo, que acabaria por se converter no energético diretor desse modelo, principalmente após a Segunda Guerra Mundial. O Paradigma dos Combustíveis Fósseis, voraz em energia e agressor do meio ambiente, começa a perder fôlego na década de setenta, com os dois choques petrolíferos. Com isso, inicia-se a transição para um novo paradigma energético-ambiental, a saber: o Paradigma das Energias Renováveis, ou melhor, o Paradigma das Fontes Renováveis de Energia, no qual assumem importância estratégica a base técnico-econômico-produtiva e a construção de uma matriz energética sustentável.

A atual fase de transição paradigmática, ou seja, a evolução do Paradigma dos Combustíveis Fósseis para o Paradigma das Fontes Renováveis de Energia implica em profundas alterações em direção a um novo modelo de sociedade, mais intensiva em tecnologia, menos energívora e lastreada no binômio «Inovação/Conhecimento», quer no que diz respeito às tecnologias de processo, quer no que se relacione com as tecnologias de uso final ou mesmo face à etapa que intermedeia as fases de produção e consumo de energia. Cabe o registo de Andrade (2004) a observar que o desenvolvimento tecnológico deve estar integrado aos problemas ambientais a uma escala mais ampla/integrativa, com o conceito de inovação a adquirir importância fulcral, havendo a necessidade de incorporar a inovação às iniciativas político-institucionais afetas ao meio ambiente, de modo a que não fique restrito ao domínio meramente corporativo.

Com isto ter-se-á uma base energoprodutiva, socioenergética e energético-ambiental dotada dos seguintes atributos: uma acentuada redução a nível do energodesperdício; uma matriz energética mais limpa/sustentável; um menor grau de perversidade/agressão em termos dos impactos sobre o meio ambiente; uma ampla interação/interpenetração entre os petroderivados e as fontes renováveis (mormente, no caso do Brasil e demais países do Trópico Úmido, das seguintes fontes de energia: hidroeletricidade, etanol, biodiesel e a biomassa como um todo); um papel mais estratégico para o gás natural, que embora sendo um combustível fóssil, poderá ter uma posição de extrema relevância enquanto energético por excelência da transição, uma vez constituir-se em fonte sofisticadora de processos, equipamentos e produtos. Para além disto há a considerar a possibilidade de se constituírem novos arranjos energoprodutivos, energotecnológicos e técnico-organizativos, quer no que diz respeito a modelos/concepções em termos da organização e gestão da produção quer quanto no que se relaciona ao parque de máquinas e equipamentos, seja na esfera da produção/distribuição de energia, seja no âmbito do uso final, em termos de produtores (agrícolas, pecuários e industriais), distribuidores ou usuário-consumidores.

O suporte fornecido pelo binômio «Inovação/Conhecimento» a esse novo modelo energéticoambiental manifestar-se-ia, de forma mais acentuada, neste ou naquele domínio da nova configuração tecnológico-produtiva afeta às novas concepções/configurações delineadas no âmbito da fase de transição. Na verdade, o binômio «Inovação/Conhecimento» servirá para lançar as bases do novo modelo, defini-lo como alternativa viável/possível, reforçar a sua evolução e assegurar, do ponto de vista energoprodutivo, energotecnológico e energo-organizativo, o estabelecimento definito do paradigma energético-ambiental do porvir. Assim sendo, a vertente da inovação avançaria mais face às tecnologias de produção/distribuição e uso final de energia, bem como com relação aos sistemas de produção e aos (re)ordenamentos mecânico-técnico-organizativos, enquanto o conhecimento estaria mais relacionado aos processos (tecnologia, métodos e aplicações), às próprias fileiras energéticas, energoprodutivas e energotecnológicas, bem como às suas respectivas cadeias de valor. Em razão disto se afirmaria o novo paradigma energético-ambiental, bem menos 
energívoro do que o modelo baseado nos combustíveis fósseis, menos nocivo ao meio ambiente (pelo contrário, com ele interativamente relacionado), de elevada intensidade tecnológica e a tomar como elemento viabilizador o binômio «Inovação/Conhecimento».

É no âmbito deste processo relativamente lento e de longa duração, instigador de elevados níveis de volatilidade, indutor de turbulências e motor da inovação tecnológica, que se (re)coloca a questão do modelo de desenvolvimento que se definirá como um novo modelo/estilo de desenvolvimento. Assim, o objetivo deste artigo é analisar a atual configuração energéticoambiental e o novo modelo de desenvolvimento que dela emerge, o qual se torna viável através do desenvolvimento tecnológico e da inovação.

\section{MATERIAL E MÉTODOS}

Do ponto de vista do constructo teórico-conceitual e metodológico afeto a este artigo, buscou-se identificar/contextualizar em termos histórico-temporais os diferentes momentos de configuração dos modelos de índole energético-ambiental, relacionando-os às respectivas fontes de energia. Estas, por sua vez, definiriam padrões produtivos e tecnológicos que teriam impactos profundamente adversos sobre o meio ambiente. Assim sendo, buscou-se analisar as experiências de industrialização a partir do processo original, com destaque para as industrializações retardatárias.

Procurou-se considerar os liames existentes entre energia, meio ambiente, economia e sociedade na definição de um novo modelo de desenvolvimento lastreado na sustentabilidade. Neste, terão um papel extremamente importante o desenvolvimento tecnológico e a inovação. Identifica-se e se caracteriza o novo padrão de desenvolvimento (o Desenvolvimento Sustentável), notadamente no âmbito da Periferia/Semiperiferia, definindo-se as singularidades, pontos de contato e fatores interativos com os modelos tradicionais. Abordou-se a questão tecnológica, em particular a inovação, com o intuito de destacar-lhe os pontos de estímulo ao Desenvolvimento Sustentável, mas também os fatores ilusórios e mistificadores, e muitas vezes inibidores, desse novo modelo de desenvolvimento. Buscou-se também analisar as relações interativas entre energia e meio ambiente, tomando-se o caso brasileiro como ilustrativo e ressaltando-se a relevância do fator tecnológico para o vingar das fontes energéticas alternativas e a configuração de um novo padrão em termos de crescimento e desenvolvimento.

Por fim, reflexiona-se acerca do relacionamento entre energia, meio ambiente e desenvolvimento, apontando-se para a tecnologia e a inovação como elementos básicos do mesmo. Quanto aos métodos e materiais utilizados, recorreu-se à pesquisa, leitura e análise de bibliografia direcionada (artigos, livros e textos), ao background e à capacidade analítico-reflexiva dos autores face ao tema.

\section{RESULTADOS E DISCUSSÃO}

\subsection{Modelo de desenvolvimento}

Em razão deste aspecto delineia-se um novo modelo ou estilo de desenvolvimento, buscando-se defini-lo a partir de uma metodologia multidisciplinar/interdisciplinar e de uma visão sistêmicointegrada, dinâmico-interativa e sistêmico-global da própria discussão e de todo o arcabouço teórico-conceitual afeto à problemática do desenvolvimento. Com isto, reconfigura-se a relação «Crescimento/Desenvolvimento», recuperando-se e aprofundando-se o debate outrora levantado pelos economistas estruturalistas latino-americanos acerca da diferença entre o processo de 
crescimento e o de desenvolvimento. Desta feita o crescimento mostra-se como um processo guiado/caracterizado por uma ótica meramente quantitativa, pela qual o desempenho de uma economia é avaliado pela performance de variáveis de índole macroeconômica (a taxa de crescimento do PIB, por exemplo) e por um viés fortemente numérico-extrapolativo acerca da trajetória e do futuro provável dessa economia.

Por seu lado, o processo de desenvolvimento envolve uma concepção/percepção mais qualitativa e menos extensiva do que aquele que caracteriza o crescimento. Pela ótica do desenvolvimento é insuficiente ter em linha de conta apenas os aspectos extensivo-quantitativos, havendo maior interesse pelos aspectos qualitativos que podem ser viabilizados pelo próprio processo de crescimento, a saber: distribuição de renda mais equitativa; disponibilidade de serviços públicos de qualidade; um setor de saúde pública eficiente; baixos níveis de mortalidade infantil; existência de um setor educativo de excelência (a todos os níveis); presença de taxas elevadas de literacia e de escolaridade; elevado percentual da população com formação universitária/pósuniversitária e/ou com alto grau de capacitação/qualificação, etc. Assim sendo, se pelo lado do crescimento tem-se uma abordagem meramente quantitativa do desempenho da economia, pelo lado do desenvolvimento tem-se uma visão qualitativa do processo, ou seja, avalia-se o impacto desse mesmo crescimento sobre o nível e a qualidade de vida da população.

De fato, se é possível adotar a expressão crescimento econômico, do lado do desenvolvimento o termo desenvolvimento econômico acaba por ter como expressões sinônimas e muito mais do que isto as seguintes: desenvolvimento socioeconômico e desenvolvimento econômico e social. Portanto, privilegia-se com isto mais do que a concepção extrapolativo-quantitativa, ou seja, o lado social do crescimento, notadamente naquilo que diz respeito à justa distribuição dos seus resultados. Por outro lado, cabe o registro de que se o conceito de crescimento econômico mostra-se insuficiente para abranger a dimensão do fenômeno em termos sociais e humanos, é necessário haver crescimento (o crescimento sustentado da economia) para que se possa promover o desenvolvimento econômico e social, muito embora esse crescimento ocorra dentro de determinados parâmetros ou regras, de modo a não agredir o meio ambiente.

Esta é a base do novo modelo/estilo de desenvolvimento que hoje toma forma e que tenta conciliar a vertente econômica com o meio ambiente e o lado social. Esta proposta parte do binômio «Economia/Sociedade», contemplado pelo desenvolvimento socioeconômico e pelo desenvolvimento econômico e social, avançando em direção ao binômio «Economia/Meio Ambiente» e chegando à concepção teórico-conceitual baseada no binômio «Desenvolvimento/Meio Ambiente. De fato, não se pode mais considerar/abordar a problemática do desenvolvimento sem levar em consideração as questões energética e meio ambiental, bem como a íntima relação e a intensa interação existente entre ambas. Na realidade, a questão energética não pode ser analisada separadamente da problemática meio ambiental, ambas integrando-se de forma sinérgico-interativa e dinâmico-sistêmica e assim se posicionando face à questão do modelo de desenvolvimento a se configurar no bojo do processo de transição paradigmática vivido pelo mundo desde os anos setenta do século XX.

Este processo de transição, por sua vez, implica na passagem do Paradigma dos Combustíveis Fósseis ao Paradigma das Fontes Renováveis de Energia, não se prendendo apenas à problemática energética, mas simultaneamente/interativamente à componente ambiental. É no âmbito deste processo relativamente lento e de longa duração, instigador de elevados níveis de instabilidade/volatilidade, indutor de turbulências e motor da inovação tecnológica, que se (re)coloca a questão do padrão que definirá um novo modelo/estilo de desenvolvimento. Este, antes do que renegar o crescimento, o redefinirá em novas bases, para além de ter a sustentabilidade como pilar de sustentação. O novo modelo de desenvolvimento surgido do trinômio sistêmico-interativo 
«Energia, Meio Ambiente e Desenvolvimento»é, de fato, o Desenvolvimento Sustentável, que tem como proposta a promoção do bem-estar em consonância com a minimização dos impactos ambientais e sócio-ambientais.

\subsection{Desenvolvimento sustentável}

Conforme é apontado por Oliveira (2002), a questão do Desenvolvimento Sustentável, de acordo com a concepção avançada por Ignacy Sachs, implicaria no fato de que o planejamento do desenvolvimento deveria considerar cinco dimensões de sustentabilidade dos sistemas econômicos, a saber: social, econômica, ecológica, espacial e cultural (ver figura 1). O objetivo da sustentabilidade social é melhorar os níveis de distribuição de renda, com o fito de reduzir a exclusão social e os níveis de apartação econômica e socioeconômica existentes entre as classes sociais. Por seu lado, a sustentabilidade econômica diz respeito a elevar a eficiência do sistema a nível da alocação/gestão de recursos. Já a sustentabilidade ecológica reporta-se à preservação do meio ambiente mas sem comprometer a oferta dos recursos naturais necessários à sobrevivência do ser humano. A seguir tem-se a sustentabilidade espacial, que remete à abordagem equilibrada da ocupação rural/urbana, bem como à melhor distribuição territorial das atividades econômicas e dos assentamentos humanos, o que passa pelas questões relacionadas ao planejamento e ordenamento territorial. Por fim, considera-se a sustentabilidade cultural, que se relaciona à alteração nos modos de pensar/agir da sociedade, de modo a nela despertar razoáveis níveis de consciência ambiental que venham de encontro à utilização de produtos que, de uma forma ou de outra, acabem por impactar o meio ambiente, de modo a promover-lhes a redução do respectivo consumo.

Figura 1- As Cinco Dimensões da Sustentabilidade

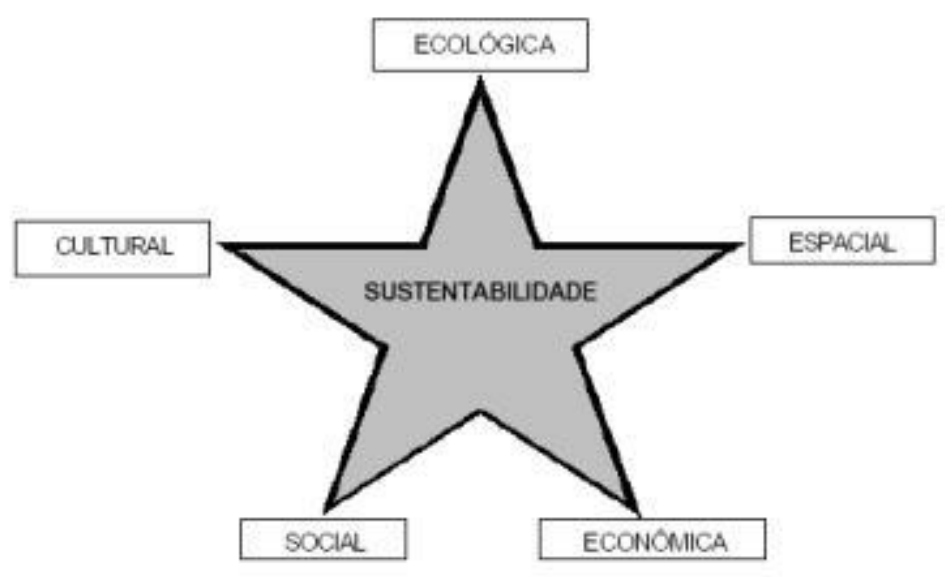

Fonte: KRAEMER, (2004)

De acordo com o que é assinalado por Oliveira (2002), considerar essas distintas dimensões (apontadas pela concepção de Ignacy Sachs) implica em criar o ambiente propício para alcançar o Desenvolvimento Sustentável. Contudo, esta concepção toma em linha de conta as carências/necessidades dos agentes econômicos (empresas, famílias e governo), que devem ser atendidas/satisfeitas. De fato, o principal objetivo do desenvolvimento é promover a satisfação das necessidades/aspirações humanas.

No caso dos países periféricos/semiperiféricos, denominados por muitos autores de países em desenvolvimento ou países em vias de desenvolvimento, grandes parcelas da população não têm as suas necessidades básicas atendidas (alimentação, vestuário, habitação, emprego, etc.). Contudo, 
para além das necessidades básicas, há que considerar as justas aspirações das populações a uma melhor qualidade de vida. Na realidade, a pobreza e injustiça endêmicas que caracterizam o mundo constituem-se em pontos de estímulo à ocorrência de crises econômicas, ecológicas, sociais, políticas, etc. Portanto, o Desenvolvimento Sustentável só se instalará com o atendimento das necessidades básicas das populações e com o proporcionar de oportunidades para a concretitização das aspirações das mesmas a uma vida melhor.

Consoante é apontado por Oliveira (2002), toda a discussão acerca da qualidade de vida é fundamental para esclarecer a controvérsia entre o conceito de crescimento econômico e o conceito de desenvolvimento, partindo-se do princípio de que é importante a ampliação do produto, mas que esta, por si só, não conduz ao verdadeiro desenvolvimento. Por esta visão, a idéia de desenvolvimento implica numa maior e melhor qualidade de vida da sociedade, com melhores níveis de distribuição de renda, saúde, educação, lazer, etc. e tudo isto relacionado ao meio ambiente. Entretanto, na teoria econômica do desenvolvimento faz-se a associação entre a industrialização e o desenvolvimento, uma vez que a indústria conduz a incrementos positivos a nível do produto (pela ótica do crescimento econômico), em razão da industrialização levar a efeitos de encadeamento. Estes, por seu lado, reforçam a crença de que a industrialização é indispensável à obtenção de maiores/melhores níveis de crescimento e qualidade de vida. De fato, a industrialização passaria a ser o grande objetivo dos países não industrializados ou semi-industrializados da Perfiferia/Semiperiferia, que sempre a viram como o passaporte para o desenvolvimento.

Oliveira (2002), destaca que na América Latina, particularmente no Brasil, nas décadas de cinquenta, sessenta e setenta, as políticas de desenvolvimento priorizaram a promoção do crescimento do produto e da renda através da acumulação de capital e do processo de industrialização. Este último baseava-se na substituição de importações. A estratégia industrializadora calcada na substituição de importações (a industrialização por substituição de importações, dita ISI) baseava-se em produzir internamente o que antes se importava, protegendo-se os produtores internos, de capital autócne ou não, da concorrência internacional através de taxas/tarifas de importação e de apoios/benefícios de carácter governamental, uma vez que a industrialização era vista como a base para se alcançar o desenvolvimento. Com isto, desestimula-se a importação de bens industriais, conduzindo os exportadores desses bens, sediados nos países pertencentes ao «Núcleo Orgânico Central» do capitalismo, a realizar inversões diretas nos países periféricos. Logo, através da proteção, cria-se um mercado interno de razoáveis proporções (notadamente no caso brasileiro) para a produção/distribuição doméstica de bens outrora importados.

Por outro lado, é bom salientar que a ISI não implica, necessariamente, no fim das importações, mas antes na sua diversificação, modificando-se-lhe a pauta, que passa a ser composta por bens de capital e outros de nível mais elevado em termos de incorporação tecnológica. Em razão disto, é através da ISI que se criam ou se reforçam as economias da Semiperiferia, ou seja, através da entrada maciça de grandes blocos de capital oriundos do centro do capitalismo, principalmente ligados ao setor industrial, que buscam oportunidades de investimento e ampliação de mercados, para além de maiores níveis de retorno para as suas inversões/atividades. Assim sendo, a implementação de uma estratégia baseada na ISI conduzirá a novas importações a nível de bens e serviços tecnologicamente mais avançados e complexos. Para muitos autores estaria aí caracterizada a perpetuação da dependência, enquanto para outros estaria aberta a possibilidade de ocorrerem sucessivos processos substituidores, os quais poderiam vir a mostrar-se como novas etapas em termos da substituição de importações, cada uma delas a incorporar níveis crescentes de sofisticação tecnológica através da implantação de setores que passem a agregar cada vez mais valor à produção industrial em particular e à economia como um todo. 
Contudo, para Oliveira (2002) o processo de industrialização promovido pelos países ditos menos desenvolvidos não ocorre de forma espontânea, antes sendo deflagrado por ações de cunho governamental, uma vez que a indústria era tida como o caminho para se alcançar o desenvolvimento. O Estado, no caso dos processos periféricos/semiperiféricos de industrialização, atua como agente regulador, produtor e indutor. Este aspecto pode ser observado em muitos países da América Latina e, principalmente, no Brasil. Os resultados desses processos industrializadores, se foram positivos por um lado (como a ampliação/diversificação da estrutura produtiva), por outro implicaram em aspectos negativos ou mesmo adversos (o alargamento da distância entre as taxas de crescimento e os indicadores de desenvolvimento). De fato, isto comprova que nem sempre a industrialização e o crescimento implicam no desenvolvimento, no sentido do desenvolvimento socioeconômico ou do desenvolvimento econômico e social e que o crescimento econômico, por si só, não é suficiente.

A presença/ação do Estado na vida econômica das nações periféricas/semiperiféricas, mormente no que diz respeito à planificação, delineamento e implementação de projetos industrializadores (a nacional-industrialização), toma como base as industrializações retardatárias do século XIX, notadamente os casos alemão e japonês, em que o Estado, nos mais diversos campos e nas mais distintas formas, vai à frente do processo de industrialização (o projeto nacionalindustrializador), de modo, inclusive, a assumir a responsabilidade por instalar muitos dos setores pesados, de larga escala, tecnologicamente mais complexos, a necessitar de novas configurações técnico-produtivas e gestionário-organizativas e a exigir elevados montantes de capital para a sua montagem, o seu arranque e a sua operação. De fato, a maior parte desse setores eram completamente novos (a química, por exemplo), surgidos no bojo da SRI e muito mais intensivos em capital e tecnologia, para além de exigirem escalas muito mais ampliadas do que os setores que lideraram a PRI, ou seja, a Revolução Industrial inglesa dos séculos XVIII e XIX.

As industrializações tardias do século XIX (tomando-se como exemplo a Alemanha e o Japão) ocorreram em contextos (temporais, geográficos e tecnológicos) completamente distintos da industrialização originária inglesa, o que exigiu uma configuração institucional bem distinta da verificada na Inglaterra. Na realidade, verificam-se algumas similitudes, notadamente nos processos industrializadores ditos da primeira vaga e iniciados no período 1840/1870, principalmente no que diz respeito ao papel assumido pela construção ferroviária e à difusão industrializadora de certos ramos da indústria, mormente o têxtil. No entanto, mesmo os processos retardatárioindustrializadores tidos como da primeira vaga, avançam em direção à segunda vaga, implantando os segmentos industriais da grande escala típicos da SRI. Por outro lado, no bojo da PRI, difunde-se a produção industrial organizada como grande indústria, definindo-se uma nova dinâmica a nível do processo de acumulação de capital, que passa a ser liderada pelo capital industrial. Portanto, as industrializações retardatárias do século XIX ocorrem no contexto da hegemonia da indústria no âmbito da economia inglesa. Em razão disto, os processos tardio-industrializadores do século XIX apresentariam características específicas a distingui-los da industrialização originária e envolveriam todo um conjunto de atores não contemplados no processo industrializador inglês, tais como os bancos por ações, os bancos de investimento, os grandes conglomerados, os cartéis, uma presença mais ativa do governo na vida econômica, etc. O processo de industrialização tardia ocorrido no século XIX em alguns países, notadamente na Alemanha e no Japão, no bojo da SRI, valeu-se de políticas econômicas favoráveis à regulação e intervenção estatal.

De fato, como é assinalado por Kemp (1974), a Alemanha saltou, no espaço de uma geração, de um conjunto de Estados economicamente atrasados para a formação de um Império unificado com uma indústria dotada de um crescimento acelerado e fundada sobre uma evoluída base tecnológica. De um ponto de vista econômico, a emergência da Alemanha como potência industrial, no século XIX, representava um desafio à posição alcançada pela Inglaterra nos mercados 
mundiais, para além de apresentar características específicas, como uma elevada concentração nos setores industriais de ponta, uma estreita associação entre a indústria e o setor bancário, bem como a combinação de uma estrutura institucional tradicional/arcaica com as formas mais desenvolvidas de capitalismo. Por outro lado, o desenvolvimento do capitalismo industrial, na Alemanha do século XIX, ocorre num contexto de papel predominante do Estado, com a existência de um setor da indústria controlada pelo Estado, o que em nada alterava a natureza capitalista do modelo de crescimento/desenvolvimento adotado.

O modelo de crescimento/desenvolvimento adotado pela Alemanha do século XIX era de nítida inspiração prussiana, cuja administração se mostrava extremamente favorável à regulação e ao intervencionismo econômico para promover o crescimento/desenvolvimento, a capacitação tecnológica e a manutenção da ordem estabelecida, conforme é apontado por Kemp (1974), que registra também que o intervencionismo/dirigismo estatal, para além de se encontrar por detrás da produção industrial integrada de larga escala, também enfatizava a educação técnico-científica, com uma clara aposta na educação e no domínio da metodologia científica aplicada aos processos afetos à organização industrial, como forma de vencer a inferioridade alemã na indústria. A existência de um forte protecionismo tarifário possibilitou uma maior plenitude de expansão ao capitalismo industrial alemão, com a débil indústria pesada ganhando competitividade através de um processo de integração/associação vertical/horizontal e tendo-se em linha de conta a estreita relação da indústria com o sistema bancário, que implicava em grandes concentrações de poder econômico.

Com relação ao Japão e ao seu projeto/processo nacional-industrializador, de acordo com o que observa Kemp (1981), a Restauração Meiji representou o fim do shogunato Tokugawa e a restauração do poder do imperador, com o fito de implementar um projeto nacional-modernizador orientado pela industrialização da economia. Para tal, a ação estatal definiria três áreas de ação, a saber: a abolição das relações feudais nos campos; o incentivo à moderna indústria e a abertura do país ao comércio com outras nações. Com a Restauração Meiji, o Japão passou, de forma acelerada, a se despreender das características do subdesenvolvimento, passando a seguir o caminho da industrialização. No Japão da Era Meiji, o Estado projetaria, de forma deliberada, a industrialização, criando/melhorando a infra-estrutura, responsabilizando-se pela importação de técnicas ocidentais, promovendo o desenvolvimento das forças de mercado, favorecendo a acumulação de capital por parte dos homens de negócios e os estimulando a avançar com investimentos na indústria. $\mathrm{O}$ Estado assumiu a importação de maquinaria estrangeira e o seu repasse, a preços módicos, aos capitalistas, de modo a fixar os custos iniciais de inversão.

Por sua vez, para Pipitone (1994), o capitalismo japonês não necessitaria, propriamente, de um espírito de independência individual para avançar em suas etapas iniciais, mas antes, pelo contrário, de uma adequação disciplinada/organizada a um projeto estatal (combinação de consenso nacionalista e eficácia oligárquica). Cabe observar que até inícios da Primeira Guerra Mundial, os investimentos governamentais, no Japão, eram enormemente superiores às inversões oriundas do setor privado. Contudo, o peso da intervenção estatal, no caso do Japão, não deve ser visto apenas sob o ponto de vista quantitativo. A própria reorganização interna do estado japonês a partir da Restauração Meiji é em si um elemento de extrema importância nesse sentido, caracterizando o elevado grau de eficiência/coordenação burocrático-administrativa do Estado Meiji. De fato, no que diz respeito a esse aspecto, observa-se que a elite político-burocrático-administrativa japonesa afeta ao Período Meiji, por exemplo, via o poderio militar como símbolo de uma economia eficiente/dinâmica.

Contudo, de acordo com o que é assinalado por Oliveira (2002), a longo prazo é praticamente impossível promover o desenvolvimento humano e social e aumentar o bem-estar da população sem que se experimente um processo de crescimento econômico. Portanto, é necessário 
haver um processo de crescimento econômico sustentado a longo prazo que implique no aumento da produção e da produtividade do sistema econômico, amplie as opções oferecidas às populações e crie oportunidades de inserção no mercado de trabalho através da criação de empregos produtivos e com remuneração adequada. Em outras palavras, nenhum país consegue atender as suas demandas sociais, laborais e meio ambientais sem o crescimento sustentado, à la longue, de sua economia.

Portanto, o crescimento econômico sustentado faz falta, não deve ser execrado e deve dar respaldo à sustentabilidade em termos de desenvolvimento. Esse crescimento deverá ser ordenado e planejado estrategicamente, de modo a mostrar-se coerente com o desenvolvimento humano e social, assim como com relação a atenuar os impactos nocivos ao meio ambiente. Por outro lado, a concepção do Desenvolvimento Sustentável deve ter na tecnologia, principalmente no que diz respeito à inovação tecnológica, um instrumento estratégico de sustentação e viabilização, notadamente no que diz respeito às tecnologias de produção, conversão e uso final de energia.

A inovação tecnológica poderá possibilitar a otimização dos encadeamentos energéticos, mormente em termos das energias renováveis, com destaque para a biomassa, viabilizando, portanto, a base energo-produtiva do modelo do Desenvolvimento Sustentável. De outro modo, a tecnologia e a inovação tecnológica podem vir a possibilitar/viabilizar interessantes arranjos do ponto de vista técnico-produtivo e energo-organizativo, de modo a superar limitações, ultrapassar determinismos e desmentir fatalismos, como parece ser o caso da polêmica «Alimentos $\mathrm{X}$ Biomassa», principalmente no caso brasileiro.

A tecnologia é de extrema importância pois possibilita o aumento da produtividade, com a consequente elevação dos níveis de competitividade da economia, de modo a se poder assegurar um crescimento econômico menos extensivo e mais direcionado, considerando-se os aspectos sociais e humanos do processo de desenvolvimento, a base de recursos naturais e os impactos sobre o meio ambiente. Entretanto, considerar a tecnologia e a inovação tecnológica com pilares do modelo de Desenvolvimento Sustentável implica em fugir de duas posições extremas, quais sejam: a visão tecnicista (a tecnologia como panacéia) e a concepção eco-fundamentalista (a negação das inúmeras possibilidades abertas pela tecnologia/inovação). O approach do Desenvolvimento Sustentável, perante a questão da tecnologia e das suas reais capacidades, adota um posicionamento equilibrado, pragmático e realista e sem tomar a tecnologia como um Deus ex machina, descortina-lhe as possibilidades e o potencial transformador.

De fato, conforme alerta Raynaut (2004), a noção de Desenvolvimento Sustentável tenta conceber um outro paradigma em termos de desenvolvimento que combine/integre diversas dimensões até então não consideradas, em que a preservação/recuperação do equilíbrio «Economia/Meio Ambiente»e «Meio Ambiente/Desenvolvimento» assume posição primordial, levando-a a ultrapassar as propostas anteriores em termos de concepções alternativas de desenvolvimento (desenvolvimento humano e ecodesenvolvimento). Contudo, o Desenvolvimento Sustentável pode apresentar várias acepções, a saber: 1- encontrar os meios técnicos para continuar a produzir ao mesmo ritmo, embora promovendo a redução dos impactos ambientais; 2 - ter como prioridade a proteção ambiental e a sustentabilidade a curto/longo prazo; 3 - privilegiar a sustentabilidade social, buscando reduzir a pobreza, considerada como principal fonte de desequilíbrio nos sistemas sociais e causa de impactos adversos sobre o meio ambiente. Em suma, o conceito de Desenvolvimento Sustentável seria relativo, variando, no espaço e no tempo, em termos de referenciais teórico-conceituais, o que conduziria à necessidade de maior pesquisa/reflexão, principalmente de carácter interdisciplinar, acerca das relações «Sociedade/Meio Ambiente».

O Desenvolvimento Sustentável, na verdade, recupera e aprofunda os conceitos de desenvolvimento socioeconômico e de desenvolvimento econômico e social, de modo a ultrapassar a crítica econômico-estruturalista e configurar, em termos teórico-conceituais, a partir do binômio 
«Economia/Meio Ambiente», um efetivo/dinâmico e sistêmico-integrado relacionamento «Meio Ambiente/Desenvolvimento», como forma a se alcançar o desenvolvimento com sustentabilidade no sentido amplo (econômico, ambiental, energético, social) e numa perspectiva estratégicoconservacionista quanto à utilização da base de recursos naturais. Isto implica também em ganhos de produtividade e crescimento da competitividade, o que envolve incorporar avanços tecnológicos a nível da produção e usos finais, num modelo/estilo de desenvolvimento que tome a tecnologia e as inovações tecnológicas como um dos seus pilares, guiando-se, de fato, pelo binômio «Tecnologia/Desenvolvimento»e pela relação «Inovação/Desenvolvimento», de modo a configurar um modelo de desenvolvimento que desprovido de tecnicismo lance as bases para um dinâmico/interativo relacionamento «Tecnologia + Inovação/Meio Ambiente».

\subsection{Energia e meio ambiente}

A questão «Energia/Meio Ambiente» mostra inúmeras faces que vão desde o domínio praticamente absoluto dos combustíveis fósseis até a entrada em cena e progressiva expansão das fontes energéticas renováveis. Conforme registram Goldemberg e Lucon (2007), os padrões atuais de produção e consumo da energia baseiam-se nos combustíveis fósseis. A consequência do predomínio das fontes fósseis de energia tem a ver com as emissões de substâncias poluentes e de gases de efeito estufa, para além do risco quanto ao suprimento de longo prazo no planeta. A mudança de todo esse quadro passa pelo incremento da participação das energias renováveis, que constituem um aspecto de significativa importância em termos de se conseguir uma maior sustentabilidade. Neste ponto, o Brasil se encontra em posição bastante favorável, contando com uma significativa parcela de eletricidade de base hídrica e também com a presença de combustíveis oriundos da biomassa (etanol e biocombustível). No caso particular da biomassa o Brasil tem como característica o desenvolvimento industrial em larga escala e a aplicação de tecnologias próprias, fruto do legado histórico da formação econômica do País e dos esforços de P\&D implementados desde a década de setenta do século passado. Para além disto, a utilização da biomassa no Brasil resulta de uma combinação de fatores, dos quais se destacam, principalmente, os seguintes: a disponibilidade de recursos abundantes e baratos, a existência de mão-de-obra de baixo custo, a rápida industrialização e a acelerada urbanização. Como exemplos desse aspecto têm-se: a produção do etanol a partir da cana-de-açúcar, o carvão vegetal oriundo de plantações de eucaliptos, a cogeração de eletricidade do bagaço de cana e o uso da biomassa em indústrias de papel e celulose (cascas e resíduos de árvores, serragem, licor negro etc.).

Para Goldemberg e Lucon (2007), há ainda a considerar o uso da lenha e do carvão vegetal, que juntos representavam cerca de $13 \%$ da matriz energética brasileira quase no fim da primeira metade do decênio transato, com o carvão vegetal a apresentar um grande potencial a nível da produção siderúrgica. O significativo crescimento do consumo de carvão vegetal deveu-se principalmente à forte expansão da sua utilização na produção de ferro gusa e à substituição do carvão mineral. Com relação ao etanol (álcool), caberia assinalar que perto de 3/4 provêm do caldo de cana-de-açúcar, que apresenta um rendimento próximo de 85,0 1/t de cana, enquanto cerca de 1/4 se origina do melaço que resulta da produção de açúcar, com um rendimento de $335 \mathrm{l} / \mathrm{t}$ de melaço. Por outro lado, há que se registrar que perto de meados da passada década, a produção total de bagaço (bagaço de cana) aproximou-se de 110 milhões de toneladas, o que possibilitou a geração de um excedente de 8,2 milhões de toneladas para usos não energéticos. Nesta mesma época, a contribuição dos produtos energéticos oriundos da cana-de-açúcar assumia, no contexto da matriz energética brasileira, um nível de contribuição superior a $13 \%$.

Por outro lado, de acordo com o que atestam Goldemberg e Lucon (2007), o que se constata é que a dependência brasileira face ao petróleo/gás natural durará ainda muito tempo, o que significa 
que o País deverá encontrar alternativas de modo a reduzir o consumo de base petrolífera-gasífera. É necessário ter em conta que no resto do mundo buscam-se alternativas às fontes poluentes da matriz energética, ou seja, aos energéticos de bases fóssil, que têm efeitos notórios em termos de impactos sobre o meio ambiente. A opção seria a via hidroelétrica, uma vez resolvidos os problemas com o licenciamento ambiental e ultrapassados os conflitos a envolver os possíveis impactos dos grandes projetos hidroelétricos sobre o meio ambiente. O Brasil não pode deixar de aproveitar o seu imenso potencial hídrico, mas deve fazê-lo com critério, avaliando os riscos meio ambientais e sociais e definindo critérios que minimizem os impactos adversos da construção das hidroelétricas. A solução passa por resolver a questão do licenciamento das usinas hidroelétricas, pelo reassentamento das populações atingidas pelos projetos hidroeléticos e pela adoção de compensações ambientais. Por estas últimas, o empreendedor deveria alocar pelo menos $0,5 \%$ do valor total da implantação de seu projeto na criação de novas unidades de conservação ou na manutenção daquelas já existentes.

Para Goldemberg e Lucon (2007), um aspecto de extrema relevância diz respeito à conservação/racionalização de energia. De fato, o que ocorre no Brasil é que a busca por uma maior eficiência em termos do consumo/utilização final de energia não se vem mostrando como opção prioritária. Para se ter uma idéia da importância estratégica da conservação/racionalização de energia, basta mencionar que se não fosse por ela, o consumo de energia na área da OCDE seria quase $50 \%$ maior do que é hoje. No caso dos contextos nacionais periféricos/semiperiféricos, notadamente no que diz respeito aos países emergentes da Semiperiferia, posição em que se coloca o Brasil, nos quais o consumo per capita de energia ainda é relativamente reduzido face to face os países ditos desenvolvidos, ou seja, àqueles que compõem o «Núcleo Orgânico Central» da economia sistema-mundo capitalista, a conservação/racionalização de energia poderia ser considerada como algo desprovido de importância ou mesmo de algum propósito. Na verdade, não se poderia esperar que medidas de conservação/racionalização de energia tivessem, nos países periféricos/semiperiféricos, tanto impacto como na área da OCDE, uma vez que a promoção do crescimento/desenvolvimento conduz, necessariamente, a maiores níveis em termos do consumo de energia. Contudo, tal não implica em não recorrer à utilização de tecnologias modernas/eficientes desde o arranque do processo de crescimento/desenvolvimento, de modo a fugir da armadilha da trajetória da ineficiência. Por fim, a conservação/racionalização de energia é a forma mais eficaz de simultaneamente reduzir os custos e os impactos ambientais, para além de diminuir a necessidade de subsídios governamentais direcionados para a produção de energia.

\section{CONSIDERAÇÕES FINAIS}

Vive-se, desde a década de setenta, a transição entre o paradigma energético-ambiental hegemônico desde a PRI (baseado nos combustíveis fósseis) e aquele que ainda não consolidou o seu domínio total (com base nas energias renováveis). Assim sendo, a problemática do desenvolvimento só faz sentido se abordada do ponto de vista da sustentabilidade, ou seja, no contexto da relação/interação «Energia, Meio Ambiente e Desenvolvimento» e inserida no âmbito da transição paradigmática em termos energético-ambientais. No bojo da relação/interação «Energia, Meio Ambiente e Desenvolvimento», define-se o novo modelo de desenvolvimento, a saber: o Desenvolvimento Sustentável.

Este modelo, aprofundizador das perpectivas afetas ao desenvolvimento socioeconómico e ao desenvolvimento econômico e social, tenta conciliar a vertente econômica com o meio ambiente e o lado social. O Desenvolvimento Sustentável baseia-se no binômio «Economia/Sociedade», configurando-se na relação/interação «Economia/Meio Ambiente» e se definindo na concepção 
teórico-conceitual baseada no binômio «Desenvolvimento/Meio Ambiente». Com isto, reforça-se a relação «Inovação/Conheccimento» na concepção e reforço do novo estilo de desenvolvimento.

Através do binômio «Desenvolvimento/Meio Ambiente», chega-se à relação «Inovação/Desenvolvimento» e à interação «Tecnologia/Desenvolvimento», moldando-se então a inter-relação «Tecnologia/Meio Ambiente», uma vez que se considera, sem cair no desvio tecnicista, que a tecnologia se constitui em elemento fundamental na promoção do desenvolvimento sem que haja impactos adversos sobre o meio ambiente. A tecnologia introduz-se a nível dos usos finais, da produção e dos processos. A inovação/tecnologia dá-se na esfera das máquinas e equipamentos e é fundamental para a viabilização e otimização do vetor substituição energética, bem como da conservação e racionalização de energia (alcance de maiores níveis de eficiência energética). Para um país emergente da Semiperiferia como o Brasil, é fundamental o vetor «Inovação/Tecnologia» na área energética para o alcance de objetivos ligados à preservação do meio ambiente. A substituição dos petroderivados por fontes renováveis de energia vai ao encontro do Desenvolvimento Sustentável, mas é também fundamental para a auto-suficiência energética do País.

Logo, a auto-suficiência não deve ser apenas a nível do petróleo (ótica exploratório-petroleira), mas em termos da energia como um todo, ou seja, só se tornando autosuficiente face à produção energética (hidroeletricidade, álcool, biocombustíveis e demais energias renováveis) e adotando a conservação/racionalização de energia como uma das bases do seu planejamento energético é que o Brasil alcançará a autosuficiência relativamente ao petróleo/gás natural.

\section{REFERENCIAS}

ANDRADE, T. D. Inovação tecnológica e meio ambiente: a construção de novos enfoques.Ambiente \& Sociedade Vol. VII n ${ }^{\circ} .1$ jan./jun. São Paulo, 2004.

COSTA, F. J. P. E RODRIGUES, M. G. Governança, Meio Ambiente e Transição de Paradigmas. Área Temática de Gestão Social e Ambiente. VII Simpósio de Excelência em Gestão e Tecnologia (VII SEGet). Resende. AEDB, de 20 a 22 de Outubro de 2010.

GOLDEMBERG, J. E LUCON, O. Energia e meio ambiente no Brasil. Estudos Avançados, São Paulo. IEA/USP, 21 (59), 2007, pp. $7-20$.

KEMP, T. La Revolución Industrial en Europa del Siglo XIX. Barcelona. Fontanella, 1974.

KEMP, T. Modelos históricos de industrialización. Barcelona. Libros de Confrontación, 1981.

KRAEMER, M. E. P. Gestão ambiental: um enfoque no desenvolvimento sustentável [Em Linha]. Disponível em «http://www.gestiopolis.com/canales3/ger/gesamb.htm». Versão não paginada, outubro de 2004.

OLIVEIRA, G. B. Uma discussão sobre o conceito de desenvolvimento. Revista da FAE, Curitiba, v.5, n.2, maio/ago. 2002, pp. 37-48.

PIPITONE, U. La salida del atraso: un estúdio histórico comparativo. México. CIDE/FCE, 1994.

RAYNAUT, C. Meio ambiente e desenvolvimento: construindo um novo campo do saber a partir da perspectiva interdisciplinar. Desenvolvimento e Meio Ambiente, n. 10, pp. 21-32, jul./dez. Curitiba. Editora UFPR, $2004 .$. 